Running Head: THEORY OF PLANNED BEHAVIOR

Effects of a Brief Intervention Based on the Theory of Planned Behavior on Leisure Time Physical Activity Participation

\author{
Nikos L. D. Chatzisarantis \\ University of Exeter, UK \\ $\&$ \\ Martin S. Hagger \\ University of Essex, UK
}

Full citation: Chatzisarantis, N. L. D., \& Hagger, M. S. (2005). Effects of a brief intervention based on the theory of planned behavior on leisure time physical activity participation. Journal of Sport and Exercise Psychology, 27, 470-487. http://dx.doi.org/10.1123/jsep.27.4.470

Manuscript re-submitted: 25 April, 2005

Correspondence: Dr. Nikos Chatzisarantis

School of Health and Exercise Sciences

University of Exeter, Heavitree Road

Exeter, EX1 2LU, UK

Email: n.chatzisarantis@exeter.ac.uk 
Theory of Planned Behavior

Effects of a Brief Intervention Based on the Theory of Planned Behavior on Leisure Time Physical Activity Participation 


\begin{abstract}
Two persuasive communications were developed to assess the utility of an intervention based on the theory of planned behavior in promoting physical activity attitudes, intentions, and behavior. One persuasive communication targeted modal salient behavioral beliefs (salient belief condition) and another persuasive communication targeted non-salient behavioral beliefs (non-salient belief condition). Results of an intervention study conducted on young people $(\mathrm{N}=83$, Mean Age $=$ $14.60, S D=.47$ ) indicated that participants presented with the persuasive message targeting modal salient behavioral beliefs reported more positive attitudes $(p<.05)$ and stronger intentions $(p=$ .059) than participants presented with the message targeting non-salient behavioral beliefs.

However, neither communication influenced physical activity participation $(p>.05)$. Path analysis also indicated that the effects of the persuasive communication on intentions were mediated by attitudes and not by perceived behavioral control or subjective norms.
\end{abstract}

Keywords: Intervention; beliefs, persuasive communication, attitudes, mediation 
Effects of a Brief Intervention Based on the Theory of Planned Behavior on Leisure Time Physical Activity Participation

In response to studies that have highlighted increased juvenile obesity rates in the United States and many European countries, researchers have highlighted the importance of regular participation in physical activities to control weight and maintain health (Hagger \& Chatzisarantis, 2005). However, as Hagger and Chatzisarantis (2005) have pointed out, even the most effective interventions do not lead to substantial improvements in adherence to physical activity (see also Haynes, McKibbon, \& Kanani, 1996). Such a disappointing trend may be due to the fact that physical activity interventions are not directly related to theories of social behavior despite that these theories have been shown to successfully predict and explain health behavior (Hardeman, Johnston, Johnston, \& Bonetti, et al., 2002). Therefore, theory-based interventions may be the first important step toward developing successful interventions. The present study uses tenets of the theory of planned behavior to develop and evaluate effectiveness of a brief intervention in changing young people's perceptions about physical activity and physical activity behavior. The study targeted young people because of the increased obesity rates that characterize this population.

\section{The Theory of Planned Behavior}

The theory of planned behavior proposes that behavior can be best predicted from a person's intention, which is an indicator of how hard people are willing to try and how much effort people plan to exert toward performance of behavior (Ajzen, 1991). The theory also proposes that intention is function of three variables: attitudes (positive or negative evaluation of performing the behavior), subjective norms (perceived influences that significant others may exert on the execution of behavior), and perceived behavioral control (the extent to which people believe that they can control performance of social behavior) ${ }^{1}$. For Ajzen (1991), the relative importance that each of these variables has on intentions can vary from individual to individual and from behavior to 
behavior. Any effort to change behavioral intentions should take into consideration whether attitudes, subjective norms, and/or perceived behavioral control carry the most weight in determining intentions and behavior.

The theory of planned behavior also deals with antecedents of attitudes, subjective norms, and perceived behavioral control using an expectancy x value model (Hagger \& Chatzisarantis, 2005). The theory proposes that attitudes arise out of a combination (multiplicative function) of beliefs that behavior will lead to certain consequences (behavioral beliefs) and evaluations of these consequences (Ajzen, 1991). Subjective norms and perceived behavioral control are also proposed to have similar origins. Subjective norms are determined by a combination of normative expectations of specific referent groups (normative beliefs) and a motivation to comply with those groups (Ajzen, 1991). Perceived behavioral control is determined by beliefs about the presence of factors that may facilitate or impede performance of behavior (control beliefs) and a perceived power of these facilitative and/or constraining factors (Ajzen, 1991). Overall, according to the theory of planned behavior, physical activity behavior and intentions can change through attitudes, subjective norms, or perceptions of control and/or by changing a combination of these three variables.

\section{Persuasive Communication as a Strategy for Behavioral Change}

Persuasive communication is a strategy of behavioral change favored by proponents of the theory of planned behavior (Ajzen, 2003). According to Bright, Manfredo, Fishbein, and Bath (1993), for a persuasive communication to effectively change intentions and physical activity behavior, it must provide belief-targeted messages that target behavioral, normative, and/or control beliefs. Development of belief-targeted messages involves the selection of statements that ultimately affect the beliefs that serve as the foundation for attitudes, subjective norms, and perceived behavioral control held by the group intended to receive the communication (Ajzen \& 
Fishbein, 1980). However, according to the theory of planned behavior, only the five to eight of the wide range of modal salient beliefs that people hold are considered to influence attitudes, subjective norms, and perceived behavioral control (Ajzen \& Fishbein, 1980). Therefore, the key to changing attitudes, subjective norms, and/or perceived behavioral control is to change the modal salient behavioral, normative, and control beliefs underlying these constructs.

It is important to note here that modal salient beliefs are not the same as important beliefs (van der Pligt \& Eiser, 1984). While modal salient behavioral beliefs are the most popular beliefs (consensual beliefs) endorsed by a group of individuals, important behavioral beliefs are idiosyncratic beliefs that individuals consider as being personally important. The two types of beliefs are different because modal salient beliefs account for less than $20 \%$ of the total number of beliefs generated by individuals (Haddock \& Zanna, 1998). Nevertheless, a common characteristic of modal salient beliefs and important beliefs is that both types of beliefs are accessible (van der Harreveld, van der Pligt, \& de Vries, 2000).

Ajzen and Fishbein (1980) also proposed that the actual structure of belief-targeted messages should consist of two parts. First, it should include a set of arguments that are in favor of the target behavior like physical activity. Second the message should aim to enhance the credibility of the arguments and/or include factual evidence designed to support the arguments (Ajzen \& Fishbein, 1980). The rationale behind enhancing credibility of arguments is that credibility leads to acceptance of the message and acceptance of the message in turns leads to belief change (Ajzen \& Fishbein, 1980).

\section{Applications of the Theory of Planned Behavior to Physical Activity and Health}

The theory of planned behavior has been one of the most influential and widely cited models of intentional behavior in social psychology (Armitage \& Conner, 2001). However, at present, there is insufficient evidence in health psychology and physical activity domains to judge whether the 
theory of planned behavior can be used to facilitate intention and behavioral change. This is because, the majority of applications of the theory of planned behavior aim to identify proximal determinants of health behavior (Armitage \& Conner, 2001) and very few studies used the theory to develop interventions and facilitate change (Hardeman et al., 2002). Although studies applying the theory of planned behavior to understand exercise behavior are necessary before interventions can be undertaken (Ajzen, 1991), the next step in theory of planned behavior research is to develop and evaluate theory-based interventions.

Recently, however, Jones, Courneya, Fairey, and Mackey (2005) did develop and evaluate a physical activity intervention that was based on the theory of planned behavior. In that intervention, Jones et al. (2005) manipulated salient normative beliefs by having an oncologist recommend physical activity to breast cancer survivors. Their study showed that participants who received an oncologist's recommendation to exercise reported more positive attitudes, stronger subjective norms, perceptions of control, intentions to exercise and reported more regular participation in physical activities than participants (in a control group) who received usual treatment and no exercise recommendation or exercise referral (see also Jones, Courneya, Fairey, \& Mackey, 2004). However, it can be argued that Jones et al. study did not provide a rigorous test of the theory of planned behavior because their intervention did not compare manipulations that targeted salient beliefs against manipulations that targeted non-salient beliefs. This is because participants (in the control group) who received a usual treatment did not receive a recommendation to exercise from a person who did not feature in the salient normative beliefs of cancer survivors (see also Jones, \& Courneya, et al., 2005; Lechner \& de Vries, 1995). In addition, because in Jones et al. (2005), participants in the control group were not recommended exercise, it is unclear from Jones et al. whether it is the manipulation of salient beliefs (i.e., the oncologists recommendation) or simply asking people exercise that changes intentions and behavior (Jackson, Lawton, Knapp, Raynor, \& 
Conner et al., in press). From both theoretical and practical points of view, providing rigorous tests of interventions based on the theory of planned behavior is important considering that according to Fishbein (1993): " the ultimate test of the theory rests upon its ability to guide the development of effective behavioral change interventions" (p. 24).

\section{Overview of the Study and Research Hypotheses}

The present study built upon previous applications of the theory of planned behavior to develop and evaluate utility of a persuasive message that targeted modal salient behavioral beliefs in changing attitudes, intentions, and the physical activity behavior of young people. We targeted modal salient behavioral beliefs because at the core of the theory of planned behavior is the assumption that messages that target modal salient beliefs are more effective in changing attitudes and intentions than messages that target non-salient behavioral beliefs (Ajzen, 2003). Because previous physical activity research has predominantly focused on non-salient beliefs (Hardman et al., 2002), the present study also evaluated the message that targeted modal salient behavioral beliefs against a message that targeted non-salient behavioral beliefs. Therefore, a unique contribution of the present study is concerned with comparison of effectiveness of an intervention that targeted modal salient behavioral beliefs against an intervention that targeted non-salient behavioral beliefs. It was hypothesized that participants who were exposed to a persuasive message that targeted modal salient behavioral beliefs would report more positive attitudes and intentions, and will be more likely to participate in physical activities than control participants who were exposed to a message that targeted non-salient behavioral beliefs $\left(H_{l}\right)$.

The present study also focused on attitudes alone because previous physical activity research has shown attitudes to carry the strongest weight in determining intentions (Hagger, Chatzisarantis, \& Biddle, 2002). In addition, an attitude-specific intervention can show impact effects and whether manipulation of behavioral beliefs influences intentions via theoretically hypothesized processes 
(i.e. via attitudes). According to Ajzen (2003), impact effects refer to the extent to which change in one variable (i.e. attitudes), produced by a persuasive communication, is offset by an unanticipated change in another variable (i.e. perceived behavioral control). Thus, pupils who are persuaded that exercising regularly is desirable because it leads to enhanced health and well being may also come to believe that exercising regularly is difficult to achieve because it prevents them from engaging in other interesting activities. Only when the persuasive communication shifts antecedents of intentions in the desired direction can the persuasive communication be expected to have a positive effect on physical activity intentions. Therefore, from a theoretical perceptive, the examination of impact effects, through an attitude-specific intervention is important considering that, according to the theory of planned behavior, manipulations of behavioral beliefs should influence intentions via attitudes and not via subjective norms or perceptions of control (Ajzen, 1991). An intervention that combined manipulations of all three antecedents of intentions could not test more specific hypothesis related to the processes by which behavioral beliefs influenced intentions because combined interventions muddle together different manipulations. Because our persuasive appeal targeted behavioral beliefs and not normative beliefs or control beliefs, it was hypothesized that our persuasive appeal would influence intentions via attitudes and not via perceived behavioral control and or via subjective norms $\left(H_{2}\right)$ (Ajzen, 1991).

\section{Method}

\section{Research Participants and Research Design}

Participants were 83 students $($ Male $=41$, Female $=42$, Age $=14.60, S D=.47)$ recruited from two comprehensive schools. Prior to data collection, we obtained informed consent from the head teachers of the schools who were asked to act in loco parentais, in accordance with the Psychological Association's ethical guidelines. The experiment employed an one-way factorial design with two conditions. In the first condition (non salient belief/control group), participants ( $N$ 
$=41$, Male $=22$, Female $=19$, Age $=14.62, S D=.47)$ were asked to participate in physical activities over the next five weeks and also studied a message that targeted non-salient behavioral beliefs. In the second condition (salient belief group), participants ( $\mathrm{N}=42$, Male $=19$, Female $=23$, Age $=14.60, S D=.47$ ) were asked to participate in physical activities the next five weeks and also studied a message that targeted modal salient beliefs.

\section{Procedure}

The experiment was run in small groups of less than five students. After participants arrived, the experimenter explained that s/he was interested in students' opinion about several health issues including physical activity. After these remarks, each participant read a definition of leisure time physical activity adopted from Godin and Shephard (1985). This definition explains the meaning of mild, moderate, and vigorous physical activity. At this point, it was made clear to participants that we were interested in the amount of physical activity that they undertook during their leisure time and not during school time. Participants were also asked to give examples of leisure time physical activities and were encouraged to ask questions about the distinction between leisure time and school-time physical activity.

After explaining the definition of leisure time physical activity, all participants completed measures of past behavior. Immediately afterwards, the experimenter informed the participants that the study required them to actually engage in vigorous physical activities during leisure time for 4 days per week and for at least 40 minutes each time over the next five weeks. Thereafter, the experimental manipulations were conducted. Manipulations took the form of written text contained in a questionnaire. It is important to stress that participants in the non salient belief group, were prompted to study a persuasive message as opposed to not studying any message, in order to reduce the likelihood that the effects of the experimental group could be attributed to non-specific features of the methodology such as demand characteristics and/or Hawthorne effect (see Jackson, \& 
Lawton et al., in press). Participants were randomly assigned to the conditions on the basis of a draw.

Finally, after five weeks, participation in physical activity during leisure-time was measured through Godin and Shephard's (1985) Leisure-Time Exercise Questionnaire. Participants reported their physical activity behavior in small groups of less than five. The experimenter reminded participants that they had been asked to consider the amount of vigorous physical activity they undertook during their leisure time only, and not physical activity done during school time. Participants were also asked to give examples of vigorous physical activities that had undertaken outside school time and they were encouraged to ask questions about leisure time physical activity.

\section{Interventions}

Communication that targeted modal salient beliefs (salient belief group). Development of the persuasive communication that targeted modal salient beliefs was based on Hagger, Chatzisarantis, and Biddle's (2001) study that identified modal salient behavioral beliefs for leisuretime physical activity in a large sample of young people. In addition, we conducted a small pilot study to confirm that students in our targeted schools displayed similar behavioral beliefs $(n=40$, Male $=23$, Female $=17$, Age $=14.2)$. In accordance with Ajzen's (2003) guidelines, we elicited modal salient behavioral beliefs by distributing an open ended questionnaire that asked participants report advantages and disadvantages associated with participation in physical activities. Specifically, the questionnaire asked participants to report (i) the advantages of engaging in active sports and/or vigorous physical activities during their leisure time for at least 40 minutes and for at least four days per week, over the next five weeks, (ii) the disadvantages of engaging in active sports and/or vigorous physical activities during their leisure time for at least 40 minutes and for at least four days per week, over the next five weeks and (iii) if there was anything else that participants associate with engaging in active sports and/or vigorous physical activities during their 
leisure time for at least 40 minutes and for at least four days per week, over the next five weeks. Modal salient behavioral beliefs were determined by counting the frequency with which behavioral beliefs featured in participants' responses (Ajzen, 2003). The three to five most frequently mentioned beliefs constituted the modal salient behavioral beliefs of participants (van der Pligt, \& Eiser, 1984). Results from our pilot study were very similar to Hagger et al.'s (2001) findings and indicated that the most popular behavioral beliefs endorsed by young people were related to "have fun", "stay fit", "improve skills", "getting an injury", and "feeling hot and sweaty".

In accordance with Ajzen and Fishbein's (1980) recommendations, the actual structure of the message that targeted salient behavioral beliefs consisted of arguments that were in favor of physical activity behavior and of credible evidence designed to support the arguments. Specifically, participants in the salient belief condition studied the following message for five minutes ${ }^{2}$ :

Scientific studies have indicated that participating in vigorous physical activities outside of your PE lessons (during your leisure time) for at least 40 minutes a time, 4 days per week, helps you get fit and stay in shape. Research has also shown that by exercising regularly you can improve your physical skills (i.e. coordination, strength) and fitness levels. Experts in the area of physical activity and health have also documented that if you exercise with care, you can reduce considerably the risk of getting an injury. In addition, you can avoid feeling hot and sweaty if you exercise for an appropriate duration (i.e. 40 minutes at a time).

Overall, exercising during your leisure time is great fun and worthwhile doing on a regular basis.

Communication that targeted non-salient beliefs (non salient belief group). Development of the persuasive appeal that targeted non-salient behavioral beliefs was based on previous physical activity research that measured non-salient behavioral beliefs of young people (Wankel, Mummery, Stephens, \& Craig, 1994). Specifically, we targeted five non-salient behavioral beliefs: "feeling 
better mentally", "relaxing and forgetting about cares", "looking better", "interference with daily routine", and "having a health condition aggravated". As with the message that targeted salient behavioral beliefs, the actual structure of the message that targeted non-salient behavioral beliefs consisted of arguments that were in favor of physical activity behavior and a second part that included credible evidence designed to support the arguments. Specifically, participants in the nonsalient/control group were prompted to study the following message for five minutes:

Scientific studies have indicated that participating in vigorous physical activities outside of your PE lessons (during your leisure time) for at least 40 minutes a time, 4 days per week, makes you look better. Research has also shown that exercising regularly helps you relax and forget about cares of daily routine. Experts in the area of physical activity and health have also documented that if you exercise with care, you can considerably reduce the risk of developing a health condition like heart disease. In addition, if you organize your time, you will discover that exercising during leisure time will not interfere with your daily routine. Overall, exercising during your leisure time helps you feel better physically and mentally and is worthwhile doing on a regular basis.

Participants in both groups were asked to study the messages, not simply read them. According to Petty and Cacioppo (1986) people are more likely to assimilate and accept information contained in a message when contents of a message are carefully studied than when they are read in a superficial manner (see also Quine, Rutter, \& Arnold, 2001).

\section{Measures of the Theory of Planned Behavior}

Three items drawn from Ajzen, (1991) were used to measure behavioral intentions. The first intention item read: "I intend to do active sports and/or vigorous physical activities, for at least 40 minutes, four days per week, during my leisure time, over the next five weeks". The second intention item read: "I plan to do active sports and/or vigorous physical activities, for at least 40 
minutes, four days per week, during my leisure time, over the next five weeks ". The third intention item read: "I am determined to do active sports and/or vigorous physical activities, for at least 40 minutes, four days per week, during my leisure time, over the next five weeks". All indicators of intention were measured on 7-point scales anchored by "strongly disagree" (1) to "strongly agree" (7). The alpha coefficient for the intention measure was satisfactory $(\alpha=.895)$.

Subjective norms were measured through two items, and on 7-point scales ranging from "strongly disagree" (1) to "strongly agree" (7). The first item read: "Others who are important to me pressure me to do active sports and/or vigorous physical activities for at least 40 minutes, four days per week, during my leisure time, over the next five weeks." The second item read: "Other people whose opinion I value would approve of my doing active sports and/or vigorous physical activities for at least 40 minutes, four days per week, during my leisure time, over the next five weeks". The alpha coefficient for the subjective norms measure was below the widely accepted minimum of .70 $(\alpha=.544)$, an artifact that has been noted in many studies using these measures (Hagger et al., 2002).

Attitudes were assessed through five bipolar adjectives. One adjective reflected moral evaluations (bad/good), two adjectives reflected instrumental evaluations (useful/useless, harmful/beneficial), and two adjectives reflected affective evaluations (unenjoyable/enjoyable, interesting/boring). All adjectives were measured on 7-point semantic differential scales (Ajzen, 1991). An example was: "For me, doing active sports and/or vigorous physical activities for at least 40 minutes, four days per week, during my leisure time, over the next five weeks....”. The alpha coefficient for the attitude measure was satisfactory $(\alpha=.904)$.

Perceived behavioral control was assessed through three items on 7-point scales (Ajzen, 1991). The first item and the second item were measured on a 7-point scales ranging from (7) "strongly agree" to (1) "strongly disagree". The first item read: "I feel in complete control over 
whether I exercise for at least 40 minutes, four days per week, during my leisure time, over the next five weeks". The second item read: "It is mostly up to me whether or not I will engage in active sports and/or vigorous physical activities for at least 40 minutes, four days per week, during my leisure time, over the next five weeks". The third item was measured on a 7-point scale ranging from (1) "no control" to (7) "complete control": "How much control do you believe you have over doing active sports and/or vigorous physical activities for at least 40 minutes, four days per week, during your leisure time, over the next five weeks. The alpha coefficient for the perceived behavioral control measure was satisfactory $(\alpha=.756)$. Finally, we measured past behavior in order to assess whether participants in the salient and non-salient/control groups had equivalent levels of past experience with physical activity. Past behavior was assessed on a 6-point scale, ranging from "not at all" (1) to "most of the days per week" (6) (Bagozzi \& Kimmel, 1995). Participants were asked to report how often they had been doing active sports, and/or vigorous physical activities for at least 40 minutes, during their leisure time, over the past 6 months.

\section{Measurement of Physical Activity Behavior}

We used Godin and Shephard's (1985) Leisure-Time Exercise Questionnaire in measuring physical activity. Independent evaluations of this questionnaire found it to be valid, reliable, easy to administer, and to display concurrent validity with objective activities and fitness indexes (Jacobs, Ainsworth, Hartman, \& Leon, 1993). In addition, the Leisure Time Exercise questionnaire has been used successfully with young people (Biddle, Goudas, \& Page, 1994). The instrument contains three open-ended questions capturing the frequency of mild, moderate, and vigorous physical activity. Because the present study targeted vigorous physical activity only, participants were asked to report the extent to which they engaged in vigorous physical activity the last five weeks. Participants reported frequency with which they exercised the past five weeks on a seven point scale ranging from "not at all" (1) to "most of the days per week" (7). 
Results

\section{Preliminary Analysis}

An analysis of variance revealed that individuals who were assigned to the "salient belief" group did not differ from those who were assigned to the "non-salient/control" group on past behavior, $(F=1.450, p>.05)$. In addition, boys did not differ from girls on past behavior $(F=.073$, $p>.05)$. Further, our sample did not consist of more girls than boys $\left(x^{2}=.012, p_{\text {asympt }}>.05\right)$. These results support the randomization of participants in experimental and control conditions. Table 1 presents descriptive statistics of psychological variables. Participants reported that they exercised an average of 3.98 days per week before and after the intervention. In accordance with assumptions underlying the theory of planned behavior (Hagger et al., 2002), Pearson's correlations supported positive relationships between intentions and physical activity participation, between perceived behavioral control and physical activity behavior, between attitudes and intentions, and between intentions and perceived behavioral control. Subjective norms were not associated physical activity intentions.

\section{Main Analysis}

In partial support of the first hypothesis $\left(H_{l}\right)$, a multivariate analysis of variance revealed a significant multivariate effect of persuasive communication $\left(F=2.784, p<.05, h^{2}=.153\right)$ on attitudes $\left(F=7.154, p<.05, h^{2}=.081\right)$ and a marginally significant effect on intentions $(F=3.665$, $\left.p=.059, h^{2}=.043\right)$. However, contrary to initial hypothesis $\left(H_{l}\right)$ the effect of persuasive communication on physical activity behavior was not significant $\left(F=.009, p>.05, h^{2}=.000\right)$. Pairwise comparisons revealed that participants in the salient belief condition reported more positive attitudes $(t=2.675, p<.05)$ and stronger intentions $(t=1.914, p<.05)$ than control participants (see Table 2). In accordance with the second hypothesis $\left(\mathrm{H}_{2}\right)$, the multivariate analysis of variance did not reveal any impact effects of persuasive communication on perceived behavioral control $(F=$ 
2.305, $\left.p>.05, h^{2}=.023\right)$ and subjective norms $\left(F=.655, p>.05, h^{2}=.008\right)($ see Table 2$)$.

We conducted a path analysis to examine utility of attitudes in mediating effects of the experimental manipulation on intentions. In particular, we estimated a model that was identical to the model proposed by the theory of planned behavior except that it estimated indirect effects (via attitudes, perceived behavioral control, and subjective norms) from persuasive communication to intentions. In addition, the hypothesized model specified effects from past behavior to all constructs derived from the theory of planned behavior and physical activity behavior. It can be suggested that the persuasive communication exerts indirect effects via attitudes, and not via subjective norms or perceived behavioral control, if (i) the hypothesized model exceeds recent criteria of good fit (Hu \& Bentler, 1999), (ii) the persuasive communication exerts statistically significant indirect effects on intentions via attitudes and (iv) the indirect effect of persuasive communication on intentions via perceived behavioral control and subjective norms are not statistically significant (Mulaik \& Millsap, 2000).

The fit of the model was evaluated on the basis of Comparative Fit Index (CFI) and Standardized Root Mean Square Residual (SRMSR) because previous research has shown that these fit indices displayed restricted random variation under various conditions of model misspecification, sample size, and estimation methods (Fan, Thomposon, \& Wang, 1999). A cutoff value close to 95 for the CFI and a cut-off value close to .08 for the SRMSR were used to evaluate the adequacy of models because the Type I and II error rates associated with these criteria are low (Hu \& Bentler, 1999). The hypothesized model was estimated using maximum likelihood method (Bentler, 1989).

Results from this analysis revealed the hypothesized model to exceed recent criteria of good fit because the CFI and SRMSR were .973 and .060 respectively $\left(x^{2}(6)=8.823, p=.112\right)$. Parameters of the model (see Figure 1) also revealed that intentions predicted physical activity behavior, whereas attitudes and perceived behavioral control predicted intentions. In accordance 
with initial hypotheses, parameter estimates revealed that the persuasive communication targeting salient behavioral beliefs exerted a statistically significant direct effect on attitudes ( beta $=.206, p<$ .05 ) and a statistically significant total indirect effect on intentions (beta $=.111, p<.05$ ). In accordance with initial hypothesis $\left(H_{2}\right)$, Sobel tests indicated that while the indirect effects of persuasive communication targeting salient behavioral beliefs on intentions via attitudes was statistically significant (test statistic $=2.52, p<.05$ ), this was not necessarily the case for indirect effects of persuasive communication on intentions via subjective norms (test statistic $=.082, p>$ $.05)$ or via perceive behavioral control (test statistic $=.982, p>.05)$ (Sobel, 1982).

\section{Discussion}

The present study represents one of the first attempts to evaluate utility of a persuasive communication directly derived form the theory of planned behavior to bring about measurable changes in young people's physical activity attitudes, intentions, and behavior. The content of the persuasive message was informed by a pilot study and by earlier empirical work that had identified modal salient behavioral beliefs in the domain of physical activity (Hagger et al., 2001). The results suggest that young people who studied a persuasive message that targeted modal salient behavioral beliefs reported more positive attitudes and stronger intentions than participants who studied nonsalient behavioral beliefs. Notably, these results cannot be attributed to human tendency to behave in a socially desirable manner or demand characteristics because like participants in the salient group, participants in the non-salient group read persuasive communications and were prompted to engage in physical activities (Jackson et al., in press). These findings confirm Ajzen's (2003) original proposition that interventions can produce change in attitudes and intentions by addressing modal salient beliefs.

In addition to replicating previous research findings (Bright, et al., 1993), the present study extends previous research on physical activity and health in several ways. Specifically, the present 
study is one of the few studies that provided a rigorous evaluation of an intervention that was directly derived from the theory of planned behavior in the domain of physical activity. Previous research in exercise and health psychology did not provide rigorous tests of theory of planned behavior because past interventions did not compare messages that targeted salient beliefs against messages that targeted non-salient beliefs (i.e. Courneya \& McAuley, 1995; Estbrooks \& Carron, 1998; Jones et al., 2005). For example, Jones et al. (2005) and Quine et al. (2001) demonstrated that interventions targeting modal salient beliefs, in the form of oncologist's recommendation or persuasive communication, produced more positive attitudes toward health behavior than interventions that did not target any belief. However, these authors did not implement an intervention that targeted non-salient beliefs, as a control intervention. As a consequence, their research design did not provide a very rigorous test of the theory of planned behavior simply because interventions that target beliefs expose people to more information and demands than interventions that do not target any belief (Hawthorne effect). Therefore, a unique contribution of the present study is the demonstration of beneficial effects of messages that target modal salient beliefs above and beyond messages that target non-salient beliefs. The practical implication of this finding is that greater attitude change can be produced by addressing salient beliefs than by introducing non-salient beliefs. Indeed, as Hardman et al. (2002) pointed out past interventions produced small to medium effects sizes (i.e. Apodaca, Woodruff, \& Candelarien et al., 1997), whereas the effect sizes of our intervention, which targeted modal salient beliefs, ranged from medium to large $\left(.042<h^{2}<.154\right) .^{3}$

Another unique contribution of the present study is concerned with investigation of impact effects and of the processes by which the persuasive communication influenced intentions. The multivariate analysis of variance revealed that our persuasive communication influenced attitudes and not subjective norms or perceived behavioral control (see Figure 1). Further, the path analysis 
and Sobel tests indicated that the effects of the persuasive communication on intentions were indirect being mediated by attitudes and not by subjective norms and/or perceived behavioral control (see Figure 1). Theoretically, these results are very consistent with tenets of the theory of planned behavior that postulate that messages targeting behavioral beliefs should influence intentions via attitudes and not via perceived behavioral control and/or subjective norms (Ajzen, 2003). The mediating role of attitudes is also consistent with a number of previous studies that supported utility of the theory of planned behavior in explaining effects of interventions. For example, Bamberg, Ajzen, and Schmidt (2003) demonstrated that introduction of a bus ticket influenced intentions to use bus via attitudes, subjective norms, and perceived behavioral control (see also Brubaker \& Fowler, 1990; Sanderson \& Jemmott, 1996). However, an important difference between the present study and previous research is that previous studies have communicated messages aiming to enhance all the underlying determinants of intentions (i.e. attitudes, subjective norms, and/or perceived behavioral control) whereas our study targeted attitudes only. The issue has theoretical importance because, as has already been explained in the introduction, interventions that manipulate all antecedents of intentions cannot shed light upon the processes by which attitudes influence intentions. Therefore, another unique contribution of the present study is concerned with delineation of the processes by which messages that target modal salient behavioral beliefs influence physical activity intentions.

Although the salient belief-based persuasive communication was successful in changing attitudes and intentions, it did not facilitate changes in physical activity participation. This may be due to a combination of five factors. First, according to the theory of planned behavior the effects of persuasive communications on behavior are mediated by two blocks of variables (see Figure 1): attitudes, subjective norms, and perceived behavioral control on the one hand and intentions on the other hand (Ajzen, 1991). Therefore, it can be expected that persuasive communications will have a 
greater impact on attitudes and a reduced impact on intentions and physical activity behavior. This is because indirect effects are always smaller than direct effects (Bentler, 1989). Consequently, the finding that our persuasive communication exerted stronger effects on attitudes $\left(h^{2}=.081\right)$ than on intentions $\left(h^{2}=.043\right)$ and physical activity behavior $\left(h^{2}=.00\right)$ is very much in accordance with theoretical tenets of the theory of planned behavior.

Second, the present intervention targeted attitudes but not subjective norms or perceived behavioral control. Although the attitude-specific intervention allowed us investigate the impact of the effects of an intervention that focused on attitudes in isolation, the tenets of the theory of planned behavior postulate that maximal changes on physical activity intentions and behavior can be facilitated by interventions that affect all three of the determinants of intentions rather than attitudes alone (Ajzen, 1991, 2003). This is particular germane for physical activity intentions considering that previous research has shown the effects of perceived behavioral control and attitudes on intentions to be additive (Hagger et al., 2002). Indeed, Jones et al. (2005) showed that a physical activity intervention influenced behavior via perceived behavioral control. Therefore, the present study might have not found changes in physical activity participation because subjective norms and/or perceived behavioral control were not manipulated. Future studies might usefully target subjective norms by having persuasive communications being delivered by people who figure in the modal salient normative beliefs of young people (i.e. friends, family members, teachers; Hagger et al., 2001). Perceived behavioral control can be manipulated by creating conditions that facilitate participation in physical activities (i.e. providing easy access to exercise facilities). Alternatively, perceived behavioral control can be increased through persuasive communications that target modal salient control beliefs.

Third, the present intervention targeted modal salient beliefs and not important or idiosyncratic beliefs (van der Pligt \& Eiser, 1984). Although modal salient behavioral beliefs and 
important beliefs are highly accessible (van der Harreveld et al., 2000), important beliefs may be more effective in promoting physical activity behavior because they evoke behavioral responses in a spontaneous manner (see Perugini, in press), that is, without the individuals' active consideration of attitudes and without individuals' awareness of the influence of that attitude (Fazio, 1990). Fourth, Fishbein and Ajzen (in press) have recently suggested that the purpose of the theory of planned behavior is to explain intentions and not necessarily behavior. For example, interventions based on this theory can produce positive intentions among non-intenders by changing behavioral beliefs, normative beliefs and/or control beliefs but the theory of planned behavior cannot help people carry out their strong intentions (Fishbein \& Ajzen, in press). Therefore, it is important to realize that the theory of planned behavior is a motivational theory that can only facilitate positive intentions among people who do not contemplate engagement in physical activities or among people who are disinclined to do so. This theory is not a volitional theory and therefore cannot facilitate enactment of behavioral intentions. The theory of planned behavior can facilitate enactment of behavioral intentions when it is applied alongside volitional techniques such as implementation intentions (see Gollwitzer, 1999; Prestwich et al., 2003; Sheeran \& Silverman, 2003) and continuation intentions (Chatzisarantis, Hagger, Smith, \& Phoenix, 2004). Therefore, the absence of an intervention effect on physical activity behavior is very much in line with purposes of the theory of planned behavior that aim to facilitate intentions and not necessarily behavior.

Fifth, it is possible that manipulation of modal salient behavioral beliefs might have produced positive effects on physical activity behavior which however might have been unstable and therefore 'washed out' after five weeks (Ajzen, 1991). Consequently, we might not have observed any effects of the intervention on physical activity behavior because behavior was not measured over a short interval of time (i.e. two weeks). The implications of such unstable effects for practice is that interventions based on the theory of planned behavior should be accompanied by 
booster sessions (Hennessy et al., 1999; Chatzisarantis, Hagger, Biddle \& Smith, 2005). In general, booster sessions can prevent undesirable change in attitudes and intentions because they are smaller doses of the original intervention that are usually delivered at a specific time soon after commencement of the intervention (Hennessy et al., 1999). In the domain of physical activity, research has suggested that interventions based on the theory of planned behavior should deliver booster sessions within five weeks interval from the commencement of the intervention because attitudes, perceptions of control, and intentions tend to decline within five weeks interval of time (Chatzisarantis et al., in press). The next step therefore for future research is to evaluate whether booster sessions increase utility of interventions based the theory of planned behavior in promoting physical activity participation.

\section{Limitations and Conclusions}

One limitation of the present study is concerned with influences that the presence of the experimenter might have exerted on subjective norms. Specifically, our intervention might have inadvertently influenced subjective norms because the intervention was delivered by an experimenter. Unfortunately, the design of our study cannot investigate influences of experimenter on subjective norms because it did not include a control condition in which the manipulation of behavioral beliefs was not delivered by an experimenter. However, it is important to recognize that effects of the theory of planned behavior intervention cannot be attributed to presence of experimenter or to subjective norms because our study (i) kept presence of experimenter constant across conditions, and (ii) showed that our experimental manipulation had an effect on attitudes and intentions even after effects from subjective norms were statistically controlled. In fact, our study shows that the manipulation of modal salient behavioral beliefs produced effects on attitudes over and above effects that might have produced by the presence of an experimenter because the only difference between the salient belief condition and the non-salient belief condition was concerned 
with manipulation of modal salient beliefs.

Another limitation of the present study is concerned with lack of measurement of behavioral beliefs, normative beliefs and control beliefs. Specifically, the present study did not measure expectancies and values people place on modal salient behavioral beliefs that underline attitudes. Measurement of modal salient behavioral beliefs is important considering that, according to the theory of planned behavior, behavioral beliefs constitute antecedents of attitudes.

In conclusion, the present study extends current knowledge by demonstrating that messages that target salient behavioral beliefs facilitate more attitude change than messages that target nonsalient beliefs. Further, it has been shown that attitude specific interventions influence intentions, but not physical activity behavior, indirectly via attitudes and not via perceived behavioral control and subjective norms. Most important, the present study is the first to report that it is possible to influence intentions by targeting attitudes only. The implications of these findings is that greater attitude change can be produced by addressing salient behavioral beliefs than by addressing nonsalient behavioral beliefs and that, at least in the context of leisure time physical activity, the theory of planned behavior provides a very useful framework in developing interventions that produce positive intentions. 


\section{References}

Ajzen, I. (1991). The theory of planned behavior. Organizational Behavior and Human Decision Processes, 50, 179-211.

Ajzen, I. (2003). Constructing a TPB questionnaire: Conceptual and methodological considerations. Retrieved April 14, 2003, from University of Massachusetts, Department of Psychology Web site: http://www-unix.oit.umass.edu/ aizen.

Ajzen, I., \& Fishbein, M. (1980). Understanding attitudes and predicting social behavior. New Jersey: Prentice Hall.

Apodaca, X., Woodruff, S., candelaria, J., Elder, J., \& Zlot, A. (1997). Hispanic health program participant and non-participant characteristics. American Journal of Health Behavior, 21, 356363.

Armitage, C. J., \& Conner, M. (2001). Efficacy of the theory of planned behaviour: A meta-analytic review. British Journal of Social Psychology, 40, 471-499.

Bagozzi, R. P., \& Kimmel, S. K. (1995). A comparison of leading theories for the prediction of goal directed behaviors. British Journal of Social Psychology, 34, 437-461.

Bamberg, S., Ajzen, I., \& Schmidt, P. (2003). Choice of travel mode in the theory of planned behavior: The roles of past behavior, habit, and reasoned action. Basic and Applied Social Psychology, 25, 175-188.

Bentler, P. M. (1989). EQS Structural Equations Program Manual. Los Angeles: BMDP Statistical Software.

Biddle, S., Goudas, M., \& Page, A. (1994). Social-psychological predictors of self-reported actual and intended physical activity in a university workforce sample. British Journal of Sports Medicine, 28, 160-163.

Bright, A., Manfredo, M., Fishbein, M., \& Bath, A. (1993). Application of the theory of reasoned 
action to the national park service's controlled burn policy. Leisure Research, 25, 263- 280.

Brubaker, R. G., \& Fowler, C. (1990). Encouraging college males to perform testicular selfexamination: Evaluation of a persuasive message based on the revised theory of reasoned action. Journal of Applied Social Psychology, 20, 1411-1422.

Chatzisarantis, N., L., D., Hagger, M., S., Smith, B., \& Phoenix, C. (2004). The influences of continuation intentions on execution of social behaviour within the theory of planned behaviour. British Journal of Social Psychology, 43, 551-583.

Chatzisarantis, N. L. D., Hagger, M. S., Biddle, S. J. H., \& Smith, B. (2005). The stability of the attitude-intention relationship in the context of physical activity. Journal of Sport Sciences, $23,49-61$.

Courneya, K., Friedenreich, C., Quinney, H., Fields, A., Jones, L. W., \& Fairey, A. S. (2004). Predictors of Adherence and Contamination in a Randomized Trial of Exercise in Colorectal Cancer Survivors. Psycho-Oncology, 13, 857-866.

Courneya, K., \& McAuley, E. (1995). Cognitive mediators of the social influence-exercise adherence relationship of the theory of planned behavior. Journal of Behavioral Medicine, 18, 499-515.

Estabrooks, P., \& Carron, A. V. (1998). The influence of the group with elderly exercisers. Small Group Research, 30, 438-452.

Fan, X., Thompson, B., \& Wang, L. (1999). The effects of sample size, estimation methods, and model specification on SEM fit indices. Structural Equation Modeling, 6, 56-83.

Fazio, R. H. (1990). Multiple processes by which attitudes guide behavior: The mode model as an integrative framework. Advances in Experimental Social Psychology, 23, 75-109.

Fishbein, M. (1993). Introduction. In D. J. Terry, C. Gallois, \& M. Mccamish (Eds.), The theory of reasoned action: Its application to AIDS preventive behavior. Oxford: Pergamon. 
Fishbein, M., \& Ajzen, I. (in press). Theory- based behavior change interventions: Comments on Hobbis and Sutton (in press). Journal of Health Psychology.

Godin, G., \& Shephard, R. J. (1985). A simple method to assess exercise behavior in the community. Canadian Journal of Applied Sport Science, 10, 141-146.

Gollwitzer, P. M. (1999). Implementation intentions: Strong effects of simple plans. American Psychologist, 54, 493-503.

Haddock, G., \& Zanna, M. On the use of open-ended measures to assess attitudinal components. British Journal of Social Psychology, 37, 129-149.

Hagger, M. S., Chatzisarantis, N., \& Biddle, S. J. (2001). The influence of self-efficacy and past behaviour on the physical activity intentions of young people. Journal of Sports Sciences, $19,711-725$.

Hagger, M. S., Chatzisarantis, N., \& Biddle, S. J. H. (2002). A meta-analytic review of the theories of reasoned action and planned behavior in physical activity: Predictive validity and the contribution of additional variables. Journal of Sport and Exercise Psychology, 24, 3-32.

Hagger, M., \& Chatzisarantis, N. L. D. (2004). The social psychology of sport and exercise. Open University.

Hardeman, W., Johnston, M., Johnston, D. W., Bonetti, D., Wareham, N. J., \& Kinmonth, A. L.

(2002). Application of the Theory of Planned Behaviour in behaviour change interventions: A systematic review. Psychology and Health, 17, 123-158.

Haynes R.B., McKibbon, K.A., \& Kanani R. (1996). Systematic review of randomised trials of interventions to assist patients to follow prescriptions for medications. Lancet, 348, 383-386. Hennessy, M., Bolan, G.A., Hoxworth, T. et al. (1999). Using growth curves to determine the timing of booster sessions. Structural Equation Modeling: A Multidisciplinary Journal, 6, 
$322-342$.

Hu, L., \& Bentler, M. (1999). Cut-off criteria for fit indexes in covariance structure analysis:

Conventional criteria versus new alternatives. Structural Equation Modeling: A

Multidisciplinary Journal, 6, 1-55.

Jackson, C., Lawton, R., Knapp, P., Raynor, D., Conner, M., Lowe, C., \& Closs, J. (in press).

Beyond intentions: do specific plans increase health behaviours in patients in primary care?

A study of fruit and vegetable consumption. Social Science and Medicine.

Jacobs, D. R., Ainsworth, B., E., Hartman, T. J., \& Leon, A. S. (1993). A simultaneous evaluation of ten commonly used physical activity questionnaires. Medicine and Science in Sports and Exercise, 25, 81-91.

Jones, L. W., Courneya, K. S., Fairey, A. S., \& Mackey, J. R. (2004). Effects of an oncologist's recommendation to exercise on self-reported exercise behaviour in newly diagnosed breast cancer survivors: A single blind, randomized controlled trial. Annals of Behavioral Medicine, $28,105-113$.

Jones, L. W., Courneya, K. S., Fairey, A. S., Mackey, J. R. (2005). Does the theory of planned behavior mediate the effects of an oncologist's recommendation to exercise in newly diagnosed breast cancer survivors? Results from a randomized controlled trial. Health Psychology, 24, 189-197.

Lencher, L., de Vries, H. (1995). Starting participation in an employee fitness program: Attitudes, social influence and self efficacy. Preventive Medicine, 24, 627-633.

Mulaik, S. A., \& Millsap, R. E. (2000). Doing the four-step right. Structural Equation Modeling, 7, 36-73.

Perugini, M. (in press). Predictive models of implicit and explicit attitudes. British Journal of Social Psychology. 
Petty, R. E., \& Cacioppo, J. T. (1986). Communication and Persuasion; Central and Peripheral Routes to Attitude Change. New York,

Prestwich, A., Lawton, R., \& Conner, M. (2003). The use of implementation intentions and their decision balance sheet in promoting exercise behaviour. Psychology and Health 18, 707-721.

Quine, L., Rutter, D., \& Arnold, L. (2001). Persuading school-age cyclists to use safety helmets: Effectiveness of an intervention based on the Theory of Planned Behaviour. British Journal of Health Psychology, 6, 327-345.

Sanderson, C., \& Jemmott, J. (1996). Moderation and mediation of HIV-prevention interventions: relationship status, intentions, and condom use among college students. Journal of Applied Social Psychology, 26, 2076-2099.

Sheeran, P., \& Silverman, M. (2003). Evaluation of three interventions to promote workplace health and safety: evidence for the utility of implementation intentions. Social Science and Medicine, $56,2153-2163$.

Sobel, M. E. (1982). Asymptotic confidence intervals for indirect effects in structural equation models. In S. Leinhardt (Ed.), Sociological Methodology (pp. 290-312). San Francisco, CA: Jossey-Bass.

van der Harreveld, F., van der Pligt, J., \& de Vries, N. (2000). The structure of attitudes: Attribute importance, accessibility and judgment. British Journal of Social Psychology, 39, 363-380. van der Pligt, J., \& Eiser, J. (1984). Dimensional salience, judgement and attitudes. In J. Eiser (Ed.), attitudinal judgement (pp. 161-178). New York: Springer-Verlag.

Wankel, L. M., Mummery, W. K., Stephens, T., \& Craig, C. L. (1994). Prediction of physical activity intention from social psychological variables: Results from the Campbell's Survey of Well-Being. Journal of Sport \& Exercise Psychology, 16, 56-69. 
Notes.

1. Ajzen (1991) stated that perceived behavioral control can also predict behavior directly when perceived behavioral control is realistic.

2. The message aimed to enhance the credibility of the arguments and of the communication. It did not aim to provide a scientific and detailed explanation of health benefits of physical activity simply because our young participants might have not comprehended the merits of such scientific explanations.

3. A note of caution should be heeded at this juncture. The effect sizes derived from the present study and from Hardman et al.'s (2002) study are not directly comparable because of differences in research designs. For example, most of the studies reviewed by Hardman et al. (2002) did not expose control participants to any message whereas the present study exposed participants in the control group to a health message. Despite those methodological differences, we decided to highlight differences in effect sizes because the use of control groups that expose participants to health messages provide more rigorous test of the effectiveness of health message that target modal salient beliefs (see Brubaker \& Fowler, 1990). 
Table 1

Descriptive Statistics

\begin{tabular}{lccccccccc}
\hline & $M$ & $S D$ & 1 & 2 & 3 & 4 & 5 & 6 & 7 \\
\hline 1. Physical activity & 3.98 & 1.18 & 1.00 & & & & & & \\
2. Intentions & 4.72 & 1.38 & .594 & 1.00 & & & & & \\
3. Attitudes & 5.28 & 1.33 & .639 & .665 & 1.00 & & & & \\
3. Subjective norms & 4.22 & 1.45 & -.059 & -.080 & .022 & 1.00 & & & \\
4. Perceived behavioral & 5.20 & 1.39 & .398 & .538 & .581 & -.177 & 1.00 & & \\
control & & & & & & & & & \\
5. Past behavior & 3.98 & 1.20 & .684 & .752 & .627 & -.121 & .532 & 1.00 & \\
6. Persuasive & - & - & .010 & .208 & .285 & -.090 & .166 & .111 & 1.00 \\
communication & & & & & & & & & \\
\hline
\end{tabular}

Note. The variable "persuasive communication" indicates membership in the non-salient belief/control group" versus "salient belief group". Correlations displayed by this variable are point bi-serial correlations. Correlations greater than .22 are significant at .05 alpha level. All constructs derived from the theory of planned behavior were measured on 7-point scales. 
Table 2

Effects of Persuasive Communication

\begin{tabular}{lcllll}
\hline & Attitude & $\begin{array}{l}\text { Subjective } \\
\text { norms }\end{array}$ & $\begin{array}{l}\text { Perceived } \\
\text { behavioral } \\
\text { control }\end{array}$ & Intentions & $\begin{array}{l}\text { Physical activity } \\
\text { behavior (5- } \\
\text { weeks) }\end{array}$ \\
\hline $\begin{array}{l}\text { Non-salient } \\
\text { group }\end{array}$ & $4.9(1.35)$ & $4.3(1.43)$ & $4.9(1.62)$ & $4.4(1.33)$ & $3.9(1.33)$ \\
Salient group & $5.7(1.21)$ & $4.1(1.47)$ & $5.4(1.09)$ & $5.0(1.39)$ & $4.0(1.03)$ \\
\hline
\end{tabular}

Note. Standard deviations are presented in parenthesis. Constructs derived from the theory of planned behavior were measured on 7-point scales. Physical activity behavior was measured in units of 1 . 
Figure Caption

Figure 1. A Path Model (Model 1) Estimating Effects of Persuasive Communication on Physical Activity Intentions and Behavior

Note. The hypothesized model was estimated on the basis of a polyserial matrix because persuasive communication was a dichotomous variable indicating membership in the "non salient belief/control group" versus "salient belief group". Past behavior exerted statistically significant effects on physical activity behavior ( $b e t a=.424, p<.05)$, intention (beta $=.326, p<.05)$, attitude $($ beta $=.303, p<.05)$, perceived behavioral control $($ beta $=.532, p<.05)$ but not subjective norms $($ beta $=-.121, p>.05)$. 


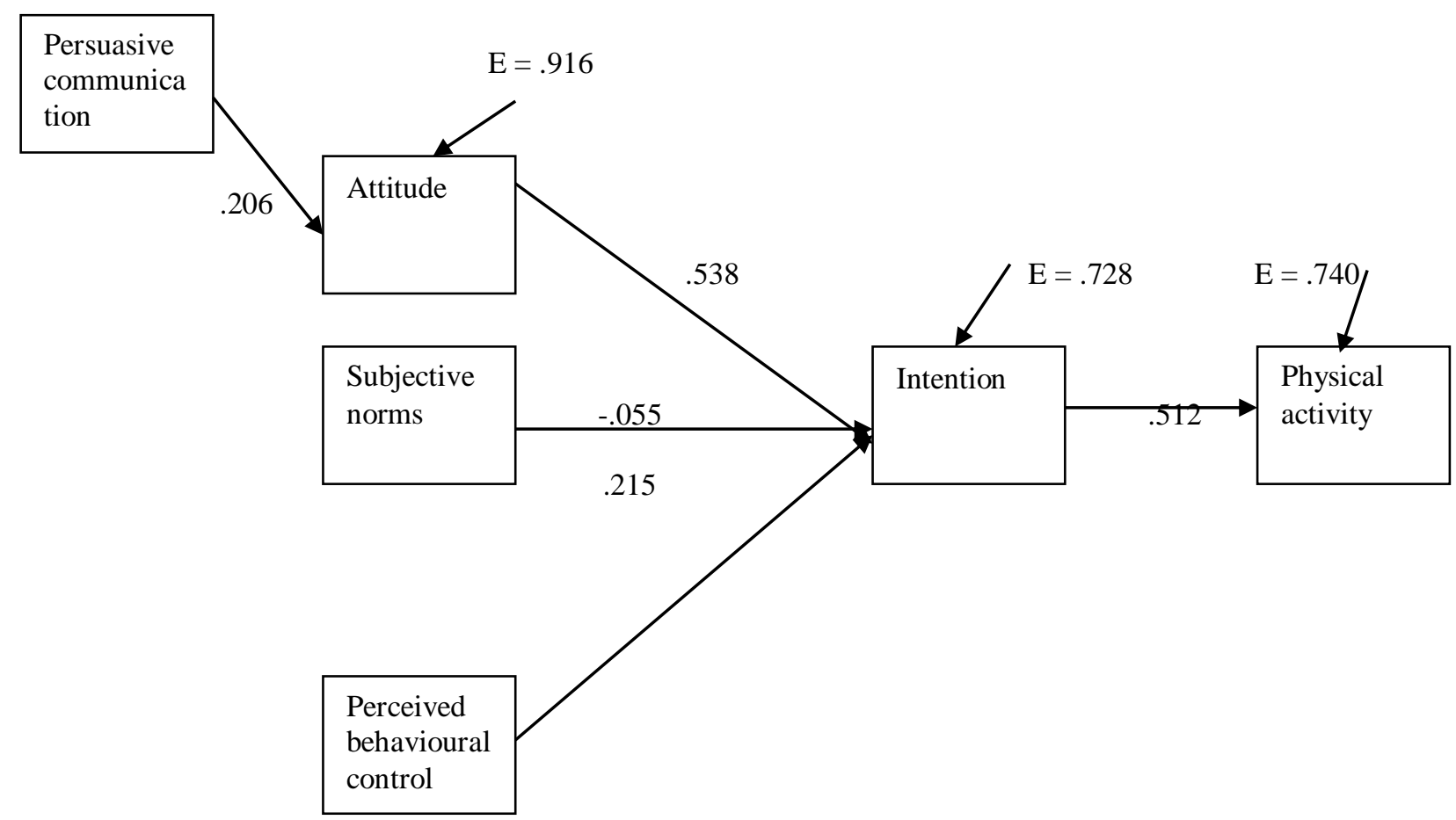

